\title{
К вопросу осуществления контроля закупок товаров, работ и услуг организаций коммерческого и государственного сектора экономики
}

\author{
С. В. Головин ${ }^{1 凶}$, М. С. Луценко ${ }^{2}$, О. О. Шендрикова \\ ${ }^{1}$ Воронежский государственный университет, Университетская пл., 1 , \\ Воронеж, Российская Федерация, 394018 \\ ${ }^{2,3}$ Воронежский государственный технический университет, Московский пр-т, 14, \\ Воронеж, Российская Федерация, 394026
}

Для цитирования: Головин С. В., Луценко М. С., Шендрикова О. О. К вопросу осуществления контроля закупок товаров, работ и услуг организаций коммерческого и государственного сектора экономики // Вестник Воронежского государственного университета. Серия: Экономика и управление. 2020. № 4 . C. 15-29. DOI: 10.17308/econ.2020.4/3189

\begin{abstract}
Предмет. На протяжении длительного времени наблюдается тенденция роста количества нарушений в области осуществления закупочных процедур. Нарушения процедуры осуществления закупки на предприятиях государственного и частного сектора экономики происходят на любой стадии процесса, начиная с проведения конкурсных процедур и заканчивая исполнением контракта. В связи с этим становится актуальным осуществление внутреннего контроля за процессом проведения закупок в государственном и частном секторе экономики.

Цели. Выявить особенности организации внутреннего контроля, сравнить процесс проведения закупок в сфере товаров работ и услуг в российских коммерческих организациях, государственных корпорациях и государственных учреждениях. Провести сравнительную характеристику закупочных процедур в государственном и частном секторе экономики.

Методология. В процессе достижения поставленных целей использовались методы научного познания: диалектический, анализа и синтеза, сравнения. Исследование построено на изучении актуальной научной и периодической экономической литературы.

Выводы. Результаты сравнения процедуры осуществления контроля закупок в государственном и частном секторе экономики позволяют выявить важные отличительные особенности контроля в государственном секторе экономики. Также на основании практики осуществления закупочной деятельности государственных корпораций рассмотрены основные причины нарушения законодательства сфере закупок товаров, работ и услуг, а также выходы из сложившейся ситуации. Предложены мероприятия мониторинга осуществления закупок, которые можно осуществлять в практической деятельности работниками как государственных, так и частных структур.
\end{abstract}

Ключевые слова: закупка товаров, работ и услуг, контроль в сфере закупок, внутренний контроль, государственная корпорация, коммерческое предприятие, контроль заказчика, государственный сектор экономики, частный сектор экономики.

\section{Введение}

Важной составляющей деятельности предприятий любой организационной формы и формы собственности является деятельность в сфере закупок товаров, работ и услуг. С целью повышения эффективности деятельности и коммерческие, и государственные предприятия проводят конкурсные закупки. Проведение закупки представляет

(c) Головин С. В., Луценко М. С., Шендрикова О. О., 2020

Вестник ВГУ. Серия: Экономика и управление. 2020. № 4. С. 15-29. собой важный аспект в обеспечении предприятий ресурсами для производства продукции, проведения работ, оказания услуг. Данная деятельность позволяет выбрать оптимальное предложение в процессе проведения закупочных процедур, обеспечивающее лучшие условия и удовлетворяющее всем критериям, предъявляемым заказчиком. Как правило, в компаниях процедурами проведения конкурса занимается специаль- 
ное структурное подразделение, зачастую именуемое отделом закупок.

В последние годы наблюдается тенденция роста количества нарушений в области взаимодействия интересов конкретного поставщика со стороны заказчика в процессе проведения государственных и частных закупок на определенных условиях. Одним из направлений решения сложившейся проблемы является внедрение системы контроля закупок в организации. Применение данной системы не требует коренного изменения структуры работы процессов.

Так как нарушение условий проведения закупки может происходить на любой стадии процесса: начиная с выбора контрагента, заключения договора поставки, заканчивая оплатой, актуальность проведения контроля, мониторинга в области закупок с целью исключения различных видов рисков, возникающих в процессе закупочной деятельности, является одним из наиболее актуальных направлений, влияющих на общую эффективность деятельности организации.

\section{Внутренний контроль процесса закупок государственных корпораций и учреждений бюджетной сферы}

Основанием для анализа процесса закупок в бюджетной сфере является единое Положение о закупках государственной корпорации. В общем виде закупка на бюджетном учреждении осуществляется в несколько этапов (рис. 1).

В процессе проведения закупки организатор не вправе создавать преимущественные условия для конкретных участников. В качестве антидемпинговых мер при проведении закупки выступают условия заключения договора с участниками. Если участником закупки, с которым заключается договор, предложено снижение НМЦ (начальной (максимальной) цена договора (лота)) на $25 \%$ и более, договор с таким участником заключается только после предоставления им обеспечения исполнения договора в размере, превышающем в полтора раза размер обеспечения исполнения договора (за исключением закупок финансовых услуг при проведении закупок, участниками которых могут быть только субъекты малого и среднего предпринимательства (МСП)).

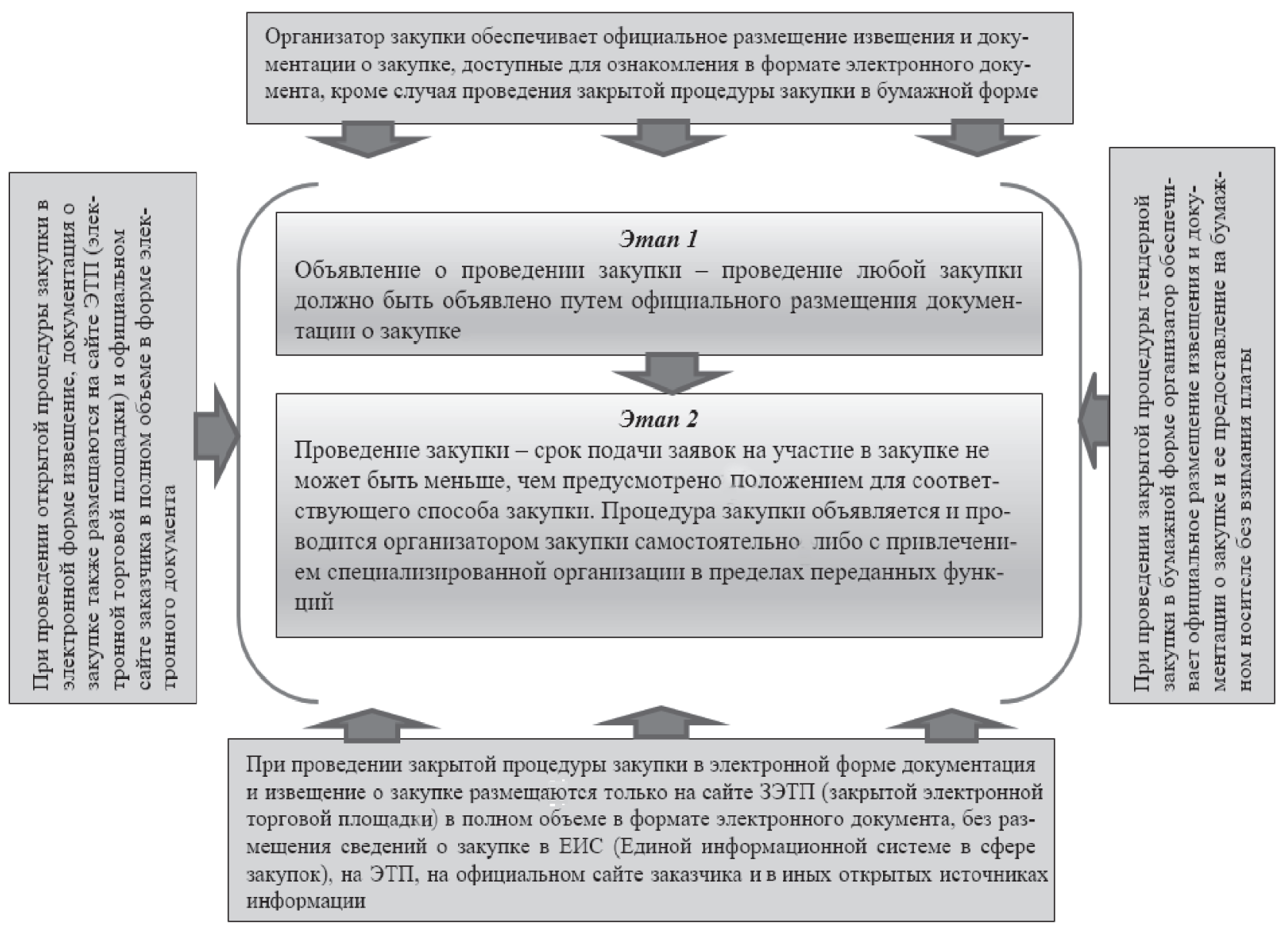

Puc. 1. Этапы проведения закупки в государственном учреждении 
К вопросу осуществления контроля закупок товаров...

Все расходы, связанные с подготовкой и подачей заявки, участник процедуры закупки несет самостоятельно. А расходы, связанные с заключением и исполнением договора закупки, ложатся на участника закупки. При этом участник закупки не вправе требовать от заказчика или организатора компенсации понесенных расходов. На рис. 2 представлена процедура проведения закупки в государственной корпорации.

В процессе проведения закупки могут быть привлечены эксперты. Чаще всего их помощь требуется на стадии исполнения договора в области деятельности организаторов закупки, заказчиков, закупочной комиссии. Эксперты проводят рассмотрение жалоб, связанных:

- с проверкой извещений и документации о закупке на предмет обнаружения коррупционных действий;

- проверкой заявок на участие в закупке в области их соответствия требованиям документации о закупке, извещения, наличия инновационных решений в заявках;

- проверкой технических условий производства продукции или образцов продукции, если подобное требование отражено в извещении и документации о закупке;

- экспертизой результатов исполнения договора, заключенного по итогам закупки, на соответствие поставленной продукции требованиям договора, целям закупки.

В исследованиях М. А. Зоткиной [12] и О. Г. Астапович [4] отмечается, что вне зависимости от способа проведения закупки, условий ее применения, видов закупочных операций в ходе исполнения договора заказчик осуществляет мониторинг исполнения договоров, который включает в себя комплекс мер по ее обеспечению:

- координация действий структурных подразделений заказчика в рамках исполнения договора;

- надлежащее исполнение обязательств по договору со стороны заказчика, в том числе выполнение встречных обязательств, приемки результатов, оплаты;

- своевременное направление информации и документов о закупках по договорам, заключенным по результатам закупки, для включения в реестр договоров согласно требованиям законодательства;

- предусмотрительный и текущий контроль за исполнением договора поставщиком, в том числе путем экспертизы представленных результатов договора и его отдельных этапов, приемки результатов исполнения договора или его отдельных этапов;

- недопущение возникновения или пресечение коррупционных фактов, связанных с исполнением договора;

- экспертиза соответствия поставщиков условиям, прописанным в извещении и документах о закупке, а также перечисленным критериям доступа к участию в закупке, их правоспособности, своевременного исполнения прав и обязанностей членов коллективного участника;

- применение к поставщику предусмотренных договором штрафных санкций или иных мер ответственности за неисполнение или ненадлежащее исполнение поставщиком своих обязательств.

Непрерывный контроль, осуществляемый на всех стадиях осуществления закупки, позволяет обеспечить ее наиболее эффективное проведение и, как следствие, повысить итоговую эффективность деятельности государственной корпорации. Как отмечает О. А. Осоедова [15] в государственных корпорациях контроль закупок может осуществляться за счет собственных или за счет внебюджетных средств госкорпорации и организаций, входящих в ее состав. Однако, говоря о непрерывности процедуры контроля, следует отдельно рассматривать ряд стадий, не охваченных на данный момент отслеживанием информации о соблюдении правил осуществления закупки, например:

- принятие проектного решения;

- исполнение гарантийных обязательств;

- использование информации о результатах исполнения контракта при проведении последующих проверок.

Контроль за осуществлением закупок осуществляется в целях:

- обеспечения устойчивого роста эффективности деятельности госкорпорации и использования ее финансовых ресурсов;

- пресечения фактов коррупции, подкупа, мошенничества в процессе закупки;

- соблюдения законодательства в отношении проведения закупок;

- обеспечения поддержки положительного имиджа отрасли.

Непрерывный контроль в сфере закупок позволяет проводить:

- профилактику нарушений; ний;

- своевременное выявление правонаруше-

- осуществление санкций по отношению к нарушителям; 


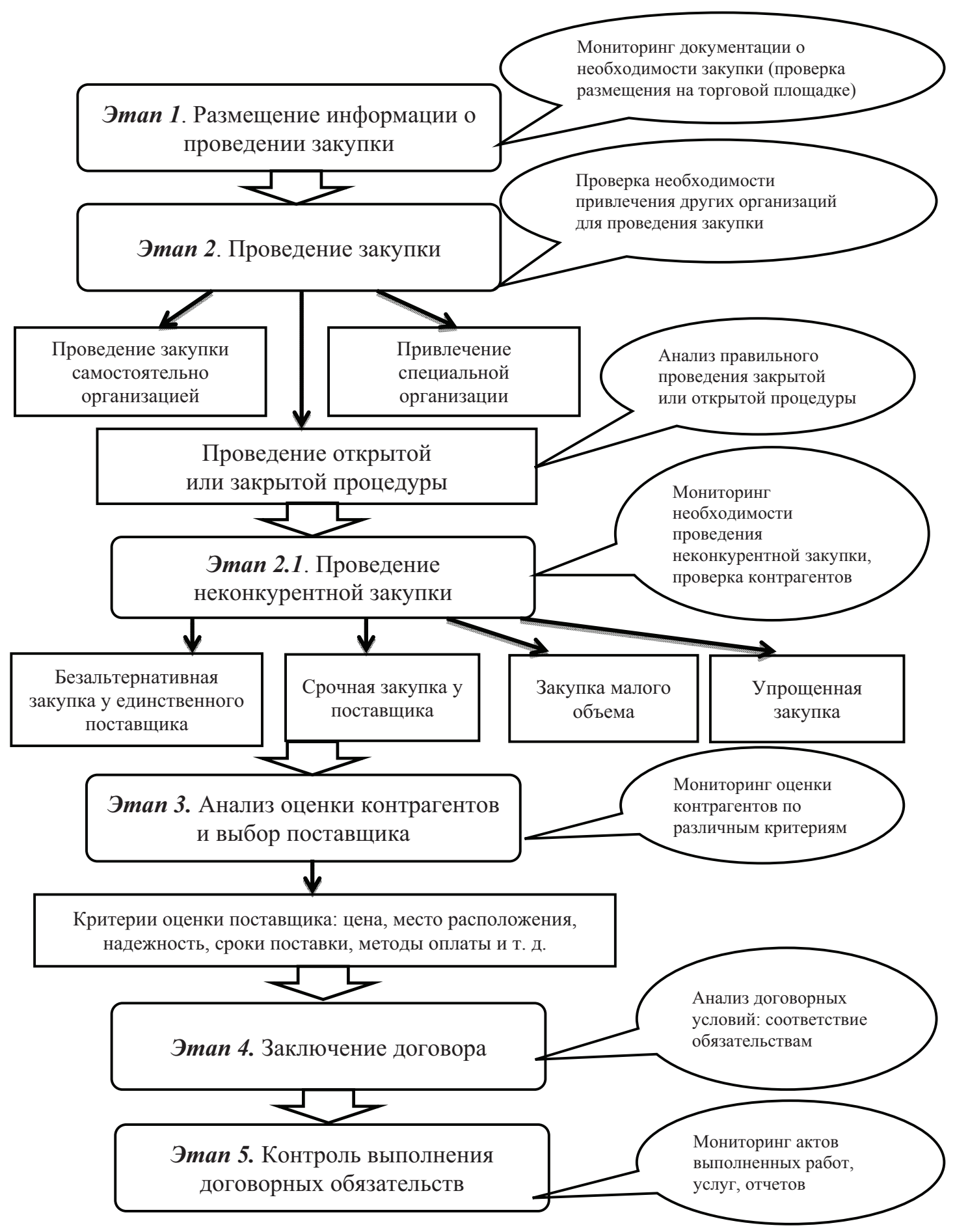

Puc. 2. Процедура проведения закупки в государственной корпорации

- разрешение возникающих споров на этапе размещения заказов.

Е. К. Богомазова [6] считает, что самой главной функцией контроля закупок в государственных корпорациях является выявление ошибок, возникающих при определении начальной цены контракта государственными заказчиками. В качестве основных причины, наиболее часто выявляемых органами контроля, выступают:

- несоответствие коммерческого предложения запросу по закупке;

- несоответствие условий расчета стоимости закупки по контрактам условиям ее исполнения;

- использование непубличной оферты; 
К вопросу осуществления контроля закупок товаров...

- рассмотрение и принятие предложений аффилированных лиц;

- заключение контрактов с юридическими лицами, ликвидированными на момент проведения закупки;

- заключение контрактов с юридическими лицами, не осуществляющими профильную деятельность;

- использование при расчете цены закупки данных о цене товаров, работ, услуг, не подходящим по условиям закупки.

Принимая во внимание опыт проведения закупочной деятельности государственных корпораций, необходимо отметить основные причины нарушений закупочного законодательства, а именно - недостаточную базу знаний сотрудников контрактных служб в области законодательных норм и правил осуществления закупок, применение данными сотрудниками формального подхода к их проведению. С целью принятия мер в связи с сложившейся ситуацией не всегда подобающего исполнения своих обязанностей сотрудниками контрактных служб в российских корпорациях происходит централизация государственных закупок, т. е. передача полномочий их проведения распорядителям бюджетных средств и уполномоченным учреждениям.

В условиях цифровой трансформации предприятий в крупных российских государственных корпорациях начат процесс переведения системы контроля закупок в информационную плоскость. Т. А. Солостина [18] отмечает, что посредством специализированных цифровых решений и конкретных программных продуктов происходит переход к автоматизированному контролю закупок. В свою очередь, в качестве функций системы автоматизированного контроля выделяют:

- автоматическое формирование и ведение реестра жалоб;

- формирование и пополнение реестра недобросовестных поставщиков;

- автоматическое составление планов контрольной деятельности;

- автоматизацию составления отчетов по результатам проведения контрольной деятельности;

- формирование и ведение реестра контролеров осуществления закупок;

- автоматическую регистрацию уведомлений о закупках у поставщика;

- автоматическую регистрацию выявляемых отклонений и возникающих нарушений в ходе проведения закупки.

\section{Процедура и особенности проведения контроля закупки в коммерческой организации}

Целью контроля закупки на коммерческом предприятии является контроль процедуры согласования затрат и проведения конкурсных процедур по выбору поставщиков, направленный на более эффективное использование ресурсов и снижение затрат компании.

После утверждения бюджета на осуществление производственной закупки инициатор (в основном сотрудник из отдела снабжения) совместно с сотрудником подразделения носителя бюджета на основании заявки на приобретение материалов, услуг и т. д. осуществляет оценку закупки на предмет необходимости проведения закупки. Если потенциальный поставщик является поставщиком из списка предпочтительных поставщиков, эксклюзивным поставщиком или поставщиком, утвержденным руководством компании, закупка осуществляется без проведения конкурсных процедур. Список предпочтительных поставщиков должен быть достаточным для осуществления возможности отбора в соответствии с требованиями технического задания. При закупке товаров и услуг, влияющих на качество продукта на протяжении всей цепи поставок, осуществляется согласование выбранных для участия в закупке поставщиков дирекцией по качеству.

Проверка осуществляется единожды перед организацией закупки на основании опросных листов, которые заполняют претенденты на участие. Только одобренные компании допускаются для участия в закупке.

При необходимости проведения конкурсных процедур осуществляется подготовка технического задания. Инициатор излагает в едином документе цели проекта и ключевые критерии для технической оценки предложений. Стандартное техническое задание состоит из следующих разделов:

- сведения о предприятии-заказчике;

- исходные данные о предмете закупки;

- описание планируемого результата;

- перечень требований к участникам;

- требования к форме подачи заявки;

- критерии оценки участников;

- предварительные сроки окончания.

После определения списка потенциальных участников закупки с учетом согласования дирекции по качеству осуществляется рассылка по e-mail поставщикам приглашений на участие. В приглашении кратко описывается суть проце- 
дуры по выбору победителя. В случае заинтересованности поставщиков в участии запрашивается письмо о сохранении получаемой со стороны компании конфиденциальной информации.

Полученные коммерческие предложения от потенциальных поставщиков передаются для анализа инициатору. Инициатор закупки проводит техническую оценку полученных предложений на полноту соответствия требованиям технического задания. Если предложение поставщика соответствует требованиям, дополнительно с ним согласовывают:

- возможность снижения цены поставки;

- информацию о предмете поставки;
- возможность увеличения отсрочки платежа;

- предоставление дополнительных условий и накопительных скидок.

После проведения конкурса осуществляется согласование листа конкурентного анализа согласно матрице согласования. Количество участников для утверждения листа конкурентного анализа должно быть не менее трех.

На основании согласованного листа конкурентного анализа осуществляется окончательный выбор поставщика для работы.

На рис. 3 представлен примерный процесс контроля закупки в коммерческой компании.

Контроль процедуры выбора поставщиков при проведении закупки и согласования затрат на закупку услуг, оборудования, сырья и т. д.
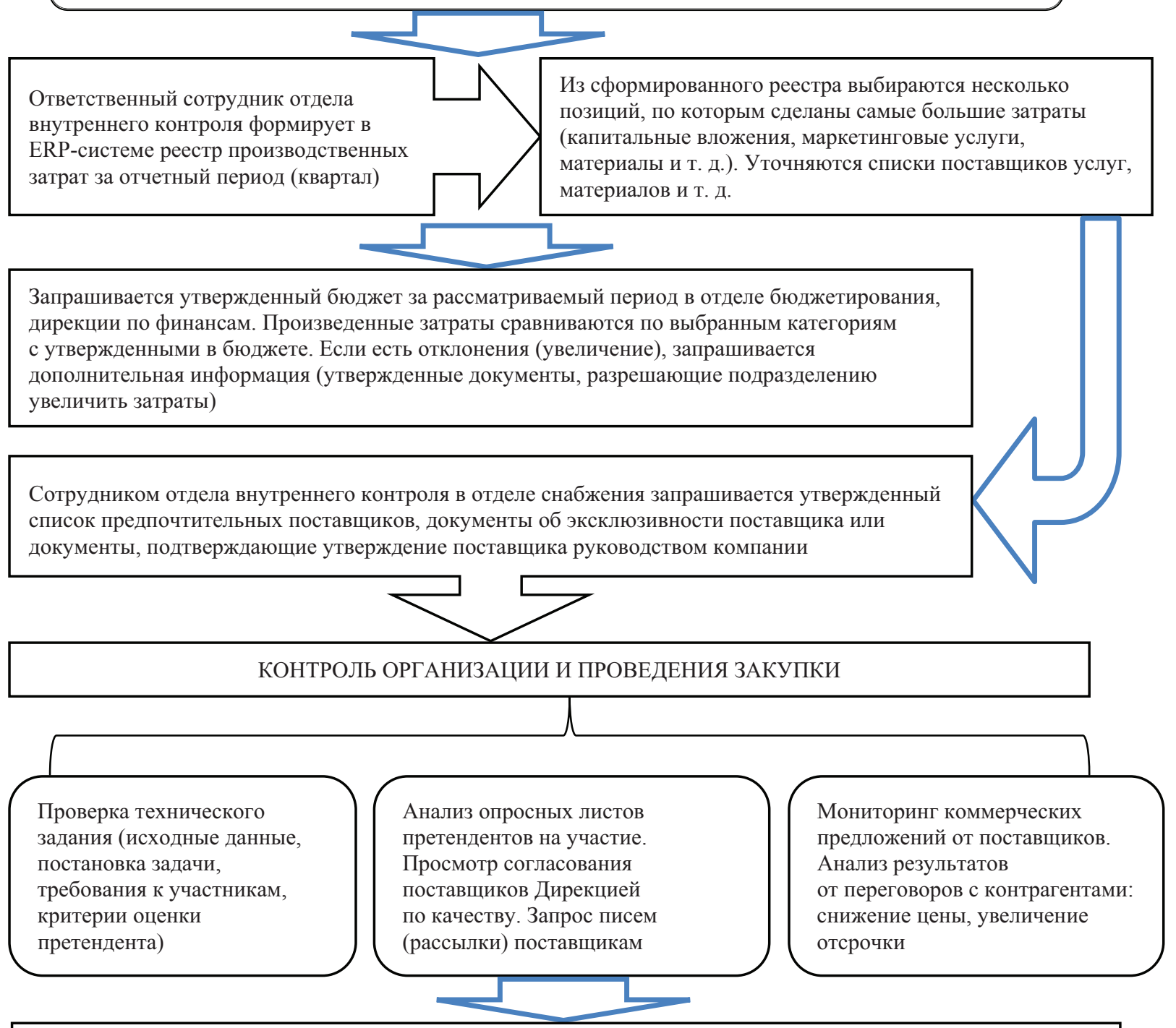

Проверка согласования листа конкурентного анализа, а также согласование выбранного поставщика (удовлетворяет ли он предъявляемым критериям)

Puc. 3. Схема контроля закупки в коммерческой компании 
К вопросу осуществления контроля закупок товаров...

В процессе проведения контрольных процедур выделим следующие наиболее часто встречающиеся злоупотребления при проведении конкурса:

а) участие аффилированных компаний;

б) участие фирм, зарегистрированных по адресам массовой регистрации;

в) закупки у одного и того же поставщика слишком широкого ассортимента товаров (услуг);

г) наличие признаков лоббирования интересов того или иного поставщика («срочность», «отсутствие альтернативы», «дополнительные гарантии, основанные на личных отношениях», и т. д.);

д) нереально сжатый срок проведения закупки, проведение конкурса с использованием малоизвестной площадки;

е) игнорирование лидеров рынка, оповещение о проведении закупки в малоизвестных источниках информации (газеты, локальные телевизионные каналы и т. д.);

ж) участие в конкурсе непрофильных компаний, отсутствие официального сайта у компании-участника;

3) отсутствие документов, подтверждающих реальное общение с представителями компаний-участников (писем, буклетов, образцов продукции и т. д.), одна из заявок приходит чуть позже других и побеждает с минимальным отрывом в цене;

и) технические требования изменяются (в сторону как снижения, так и повышения) после проведения конкурса, претенденты жалуются на отсутствие обратной связи;

к) участники работают на субподряде у победителя, победитель предложил демпинговую цену/нереальные сроки.

\section{Сравнительная характеристика закупок в государственном \\ и частном секторе экономики}

С учетом динамичных изменений внешней среды предприятий и организаций система закупок находится в стадии адаптации и совершенствования, приобретая свойство оперативно реагировать на изменение стратегических задач национальной экономики. Недостаточная гибкость и сложность ранее действующей системы, низкая степень контроля со стороны государства обусловливали недостаточную эффективность государственных закупок. Таким образом, на эффективности осуществления закупки положительно сказывается увеличение степени государственного присутствия в процедуре его осуществления и контроля. В рамках чего важнейшими задачами являются повышение прозрачности диверсификации, контрактной системы, уровня компетентности участников закупок.

В соответствии с исследованием О. Е. Устиновой [19] государственная закупка не отличается от покупки любой коммерческой компании, если не рассматривать ее в разрезе отличительных особенностей. Одной из таких особенностей выступает обязательность проведения государственной закупки. Это означает, что предприятие совершает закупку в силу предписанных ему законодательными и различными нормативными правовыми актами функциональных обязанностей. В табл. 1 представлена характеристика закупок предприятий государственного и коммерческого секторов экономики, позволяющая выделить их отличительные черты.

Таким образом, еще одной важной отличительной чертой в отношении проведения закупок на предприятиях государственного сектора выступает определение целесообразности самой закупки, которая определяется соответствующими государственными нормативно-правовыми актами, регламентирующими осуществление приобретения исключительно нужных, полезных, качественных товаров и услуг. Э. А. Халикова [20] считает, что соблюдение данного условия позволяет избежать перерасхода денежных ресурсов государства и необоснованных материальных затрат и потерь при хранении запасов и, как следствие, дефицита финансирования последующих закупок товаров, работ и услуг.

\section{Мероприятия в рамках мониторинга за осуществлением закупок}

В целом необходимо отметить, что контроль за осуществлением закупок в государственных корпорациях и на коммерческих предприятиях направлен не только на выявление отклонений в процедуре их осуществления, а также на определение эффективности работы субъектов, его осуществляющих, и выявление достаточности и систематичности его осуществления.

Г. Г. Сайфулова [17] и Т. Б. Лейбурт [13] отмечают, что система контроля осуществления закупок организаций любой формы собственности признается эффективной в случае наличия в ней инструментов, позволяющих снижать вероятность возникновения ошибок и отклонений в ведении закупки наряду с осуществле- 


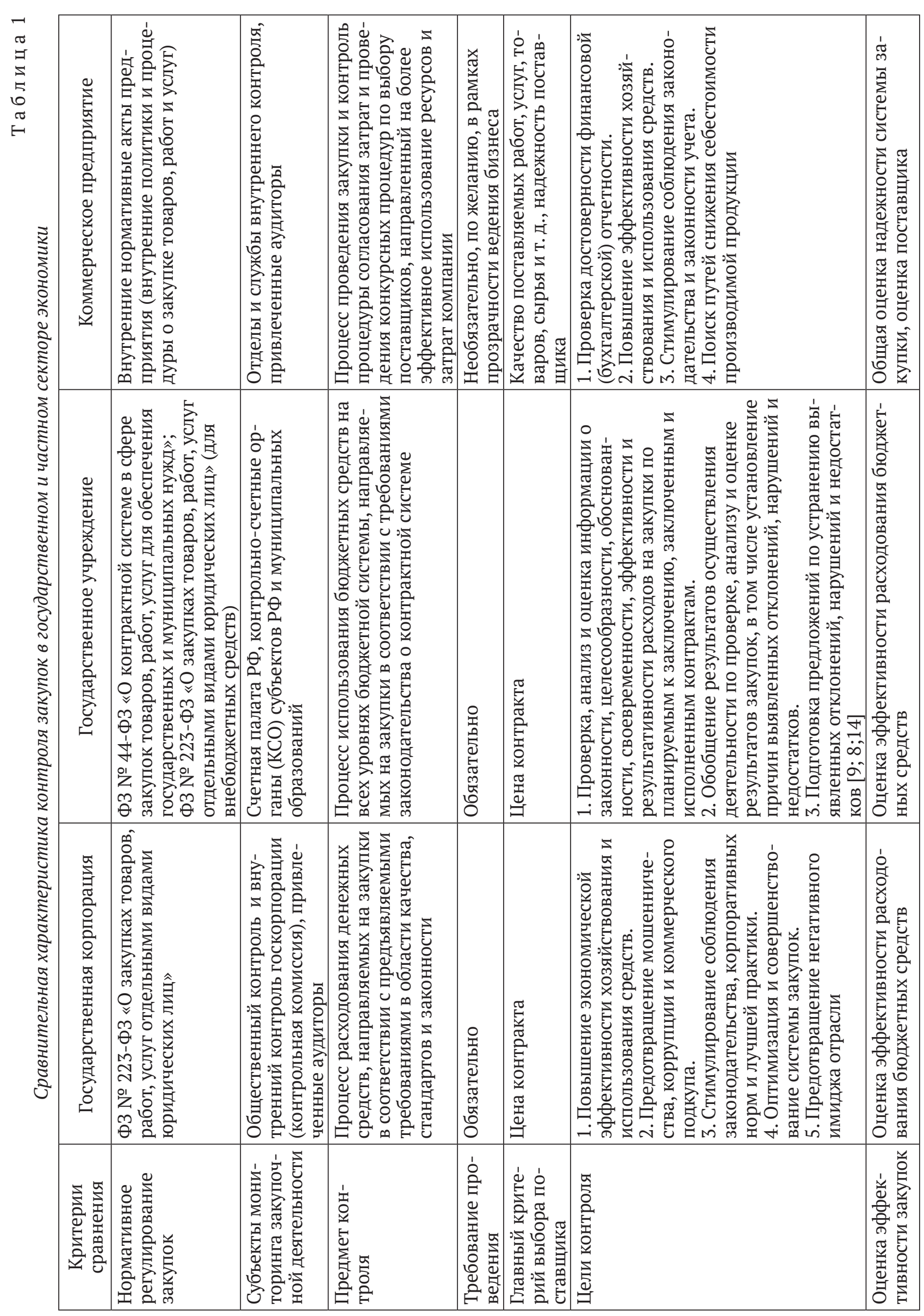


К вопросу осуществления контроля закупок товаров...

нием идентификации возникающих ошибок и отклонений. В соответствии с выявленными особенностями, отличающими эффективную систему внутреннего контроля закупок, на рис. 4 представлена рекомендуемая процедура организации проведения контроля закупочной деятельности. В таблице 2 перечислены мероприятия в рамках мониторинга за осуществлением закупок в соответствии с представленной процедурой организации системы контроля, раскрыта сущность и условия осуществления каждого из перечисленных мероприятий.

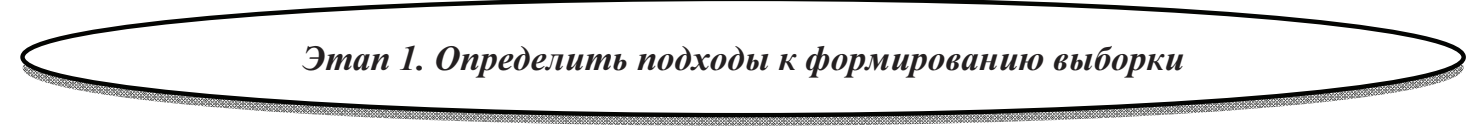

(использовать метод стратификации, при котором генеральная совокупность разделяется на группы (страты) на основе одной или нескольких характеристик)

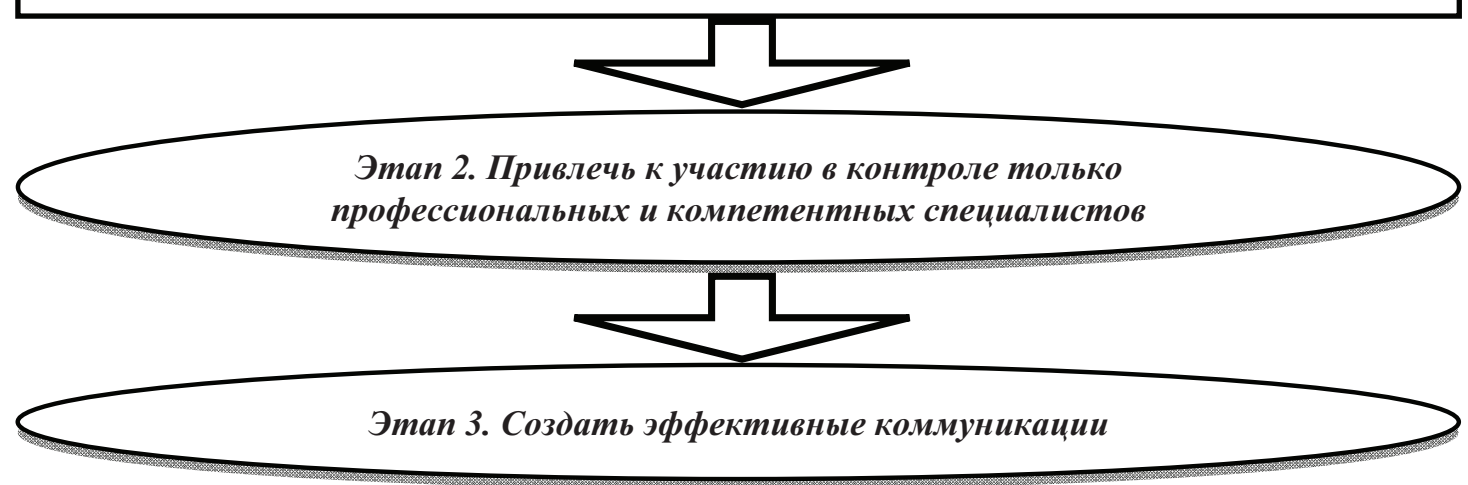

(важно избегать обвинений и выстроить конструктивный диалог со всеми заинтересованными сторонами). Если в ходе процедур контроля удалось вскрыть серьезное злоупотребление, привлекайте к дальнейшему расследованию коллег из СБ

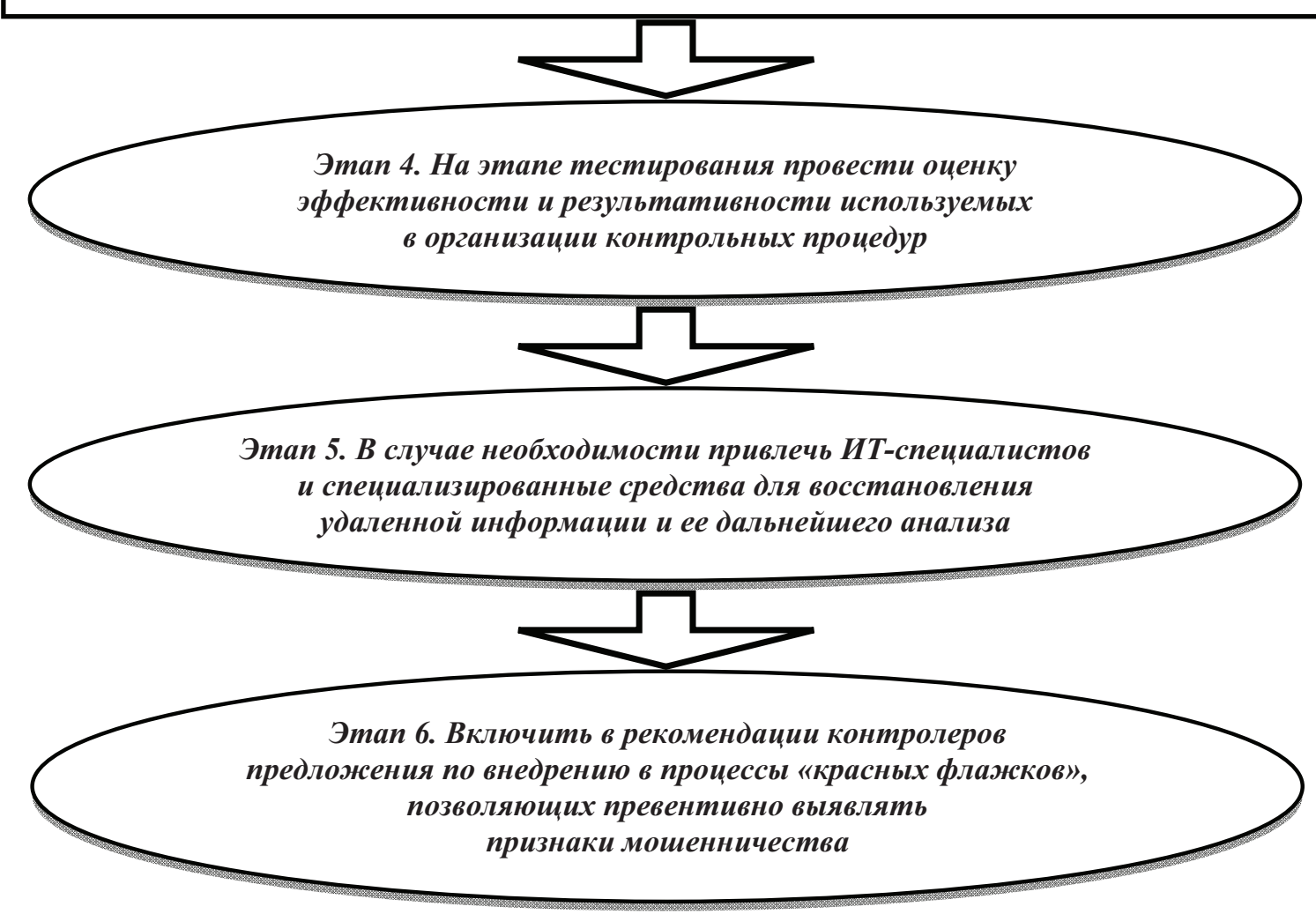

Puc. 4. Рекомендуемая система контроля закупочной деятельности в организации 


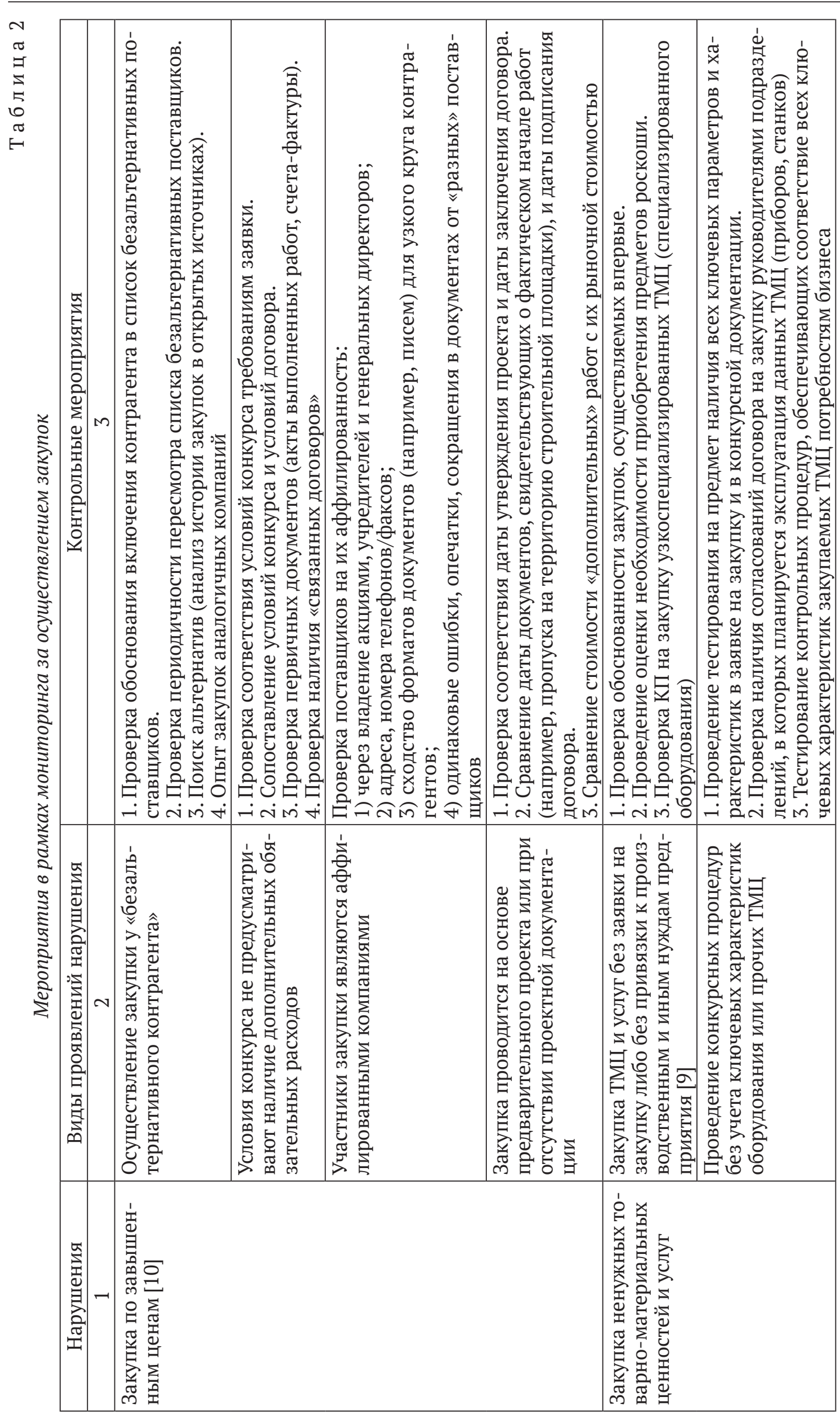


К вопросу осуществления контроля закупок товаров...

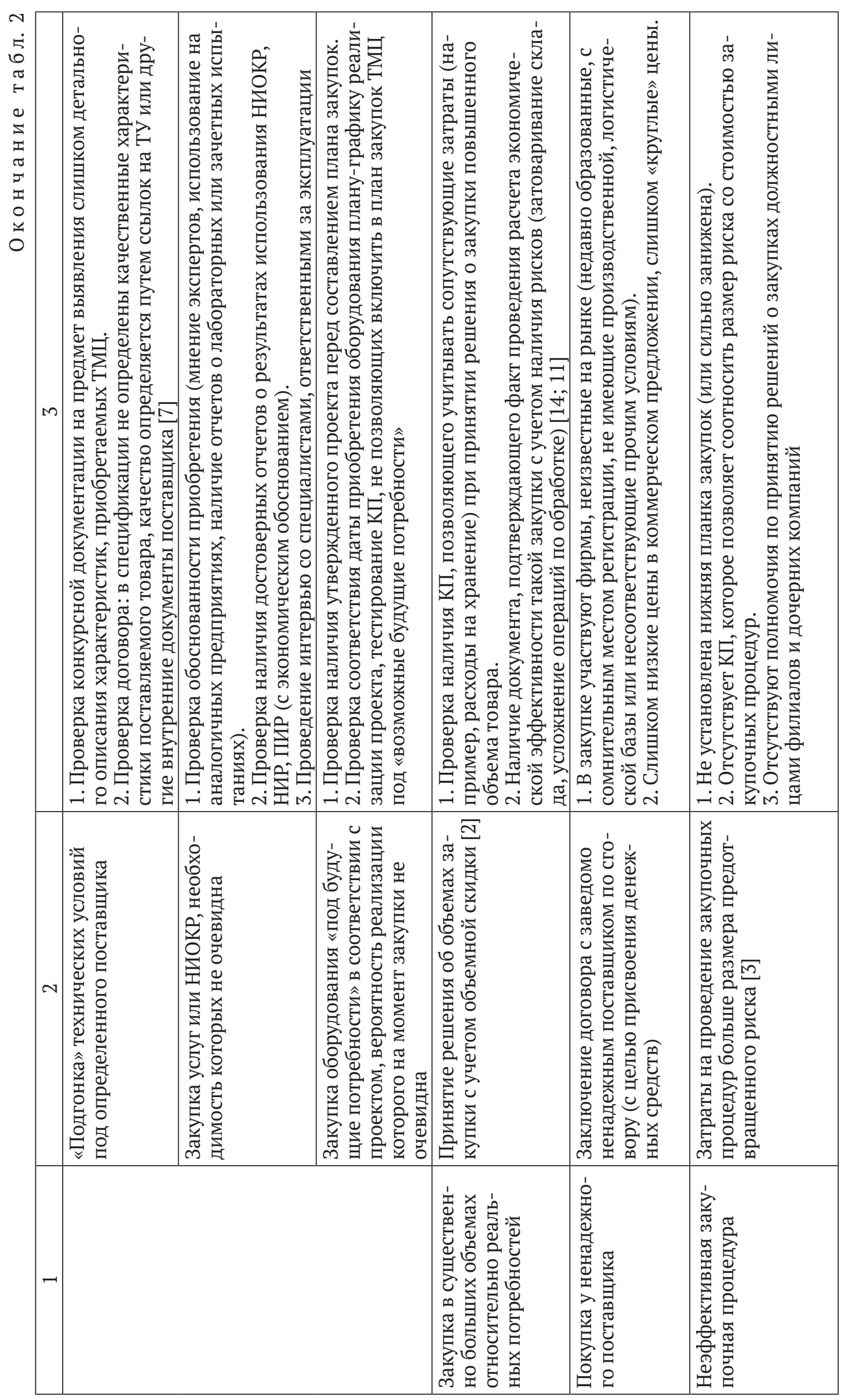




\section{Заключение}

Таким образом, по результатам сравнения процедуры осуществления контроля закупок в государственном и частном секторе экономики можно сделать вывод, что важной отличительной особенностью контроля в государственном секторе экономики является оценка целесообразности использования бюджетных средств. Огромное значение уделяется целевому и эффективному расходованию бюджетных средств на покупку, а также определению меры соблюдения требований количественной разумности и соразмерности осуществляемой покупки.

На основании практики осуществления закупочной деятельности государственных корпораций основными причинами нарушения закупочного законодательства является недостаточная база знаний сотрудников контрактных служб государственного заказа законодательных норм в сфере закупок и формальный подход к их проведению. В качестве компенсационной меры выступает централизация государственных закупок, а именно осуществление их главными распорядителями

\section{Библиографический список}

1. Antonopoulos A. M. Mastering Bitcoin. CA : Sebastopol, O’Reilly Media, Inc., 2014.

2. Peemöller V., Kregel J. Grundlagen der Internen Revision: Standards, Aufbau und Führung. Berlin, Schmidt, 2010.

3. Schneider D. Controlling als postmodernes Potpourri // Controlling. 2005. Vol. 17. P. 65-69.

4. Астапович О. Г. Современные международные тендеры: понятия, особенности, тенденции // Право. Экономика. Психология. 2020. № 1 (17). C. $10-15$.

5. Бахвалов В. Л. Вопросы эффективного контроля в сфере государственных закупок // Бюджет. 2019. № 3 (195). С. 45-47.

6. Богомазова Е. К. Основные цели и задачи аудита закупок // Инновации и инвестиции. 2018. № 5. C. $155-156$.

7. Вайпан B. А. Состояние, проблемы и перспективы развития контрактной системы // Журнал предпринимательского и корпоративного права. 2017. № 4. C. 9-12.

8. Головин С. В. Особенности современного этапа осуществления контроля в сфере закупок государственных учреждений // Аудит. 2020. № 10. C. 30-34.

9. Головин С. В., Капранчиков И. С. Особенности закупочной деятельности в сфере здравоохране- бюджетных средств и уполномоченными учреждениями, что на сегодняшний день весьма актуально и встречается в ряде российских корпораций.

В.Л.Бахвалов [5], П.А. Паулов [16] отмечают, что контроль закупок в государственных корпорациях и коммерческих предприятиях направлен не только на выявление отклонений в процедуре их осуществления, но также на определение эффективности деятельности субъектов контроля и достаточности и систематичности осуществляемых процедур контроля. Система контроля осуществления закупок организации любой формы собственности признается эффективной в случае наличия в ней инструментов, позволяющих снижать вероятность возникновения ошибок и отклонений в ведении закупки наряду с осуществлением идентификации возникающих ошибок и отклонений.

\section{Конфликт интересов}

Авторы декларируют отсутствие явных и потенциальных конфликтов интересов, связанных с публикацией настоящей статьи.

ния // Современная экономика: проблемы и решения. 2019. № 4 (112). С. 16-23.

10. Горлова И. Р., Мусина Д. Р., Болдырев Е. С. Совершенствование закупочного процесса на нефтедобывающем предприятии // Евразийский юридический журнал. 2018. № 1. С. 383-385.

11. Горюнова В. В. Аудит в сфере закупок товаров, работ и услуг для государственных нужд // Экономика и предпринимательство. 2016. № 12-1 (77). С. 907-909.

12. Зоткина М. А. Условия участия автотранспортных предприятий в тендерных процедурах // Вестник Сибирского государственного автомобильно-дорожного университета. 2017. № 4-5 (5657). С. $159-165$.

13. Лейберт Т.Б., Халикова Э. А., Третьяков Т.А. Комплаенс-контроль закупок, связанных с инвестиционной деятельностью компаний // Экономика и управление. 2019. № 6 (150). С. 119-122.

14. Макарова В. В. Оценка эффективности контрактной системы: российский и зарубежный опыт // Актуальные проблемы и перспективы развития экономики: российский и зарубежный опыт. 2020. № 1 (26). С. 21-25.

15. Осодоева О. А., Санжин Б. Б., Цыремпилов Д. А. К вопросу о развитии системы государственных закупок на примере Республики Бурятия // Экономический вестник Восточно-Сибир- 
ского государственного университета технологий и управления. 2018. № 6. С. 21-30.

16. Паулов П. А., Силантьева К. В. Государственное регулирование закупочной деятельности // Бюллетень науки и практики. 2018. Т. 4, № 12. C. 442-446.

17. Сайфуллова Г. Г., Хайтабаев В. А. Процедуры внутреннего контроля при подготовке и проведении тендеров // Наука и образование транспорту. 2018. № 1. С. 160-161.

18. Солостина T. А. Аудит в сфере закупок в развитии новой системы государственного прокьюремента // Вестник Российского нового университета. Серия: Человек и общество. 2019. № 3. С. 73-79.

19. Устинова О. Е. Зарубежный опыт управления государственными закупками и особенности российской практики в условиях реформирования контрактной системы // Инновационное развитие экономики. 2019. № 2 (50). С. 183-187.

20. Халикова Э. А., Сафиуллин И. И. Совершенствование системы управления корпоративными закупками // Евразийский юридический журнал. 2017. № 9. С. 384-385.
Головин Сергей Владимирович, кандидат технических наук, доцент кафедры экономического анализа и аудита, Воронежский государственный университет, Воронеж, Российская Федерация

E-mail: golovin@econ.vsu.ru

ORCID ID: 0000-0002-9722-4523

Луценко Марина Сергеевна, кандидат экономических наук, доцент кафедры экономической безопасности, Воронежский государ- ственный технический университет, Воронеж, Российская Федерация

E-mail: luchiksan@rambler.ru

ORCID ID: 0000-0002-2137-164X

Шендрикова Олеся Олеговна, кандидат экономических наук, доцент кафедры экономической безопасности, Воронежский государственный технический университет, Воронеж, Российская Федерация

E-mail: oli-shendro@yandex.ru

ORCID ID: 0000-0001-8975-2660

Поступила 30.10.2020

Подписана в печать 15.12.2020 


\title{
On the issue of control over the procurement of goods, works and services of organizations of the commercial and public sector of the economy
}

\author{
S. V. Golovin ${ }^{1}$, M. S. Lutsenko ${ }^{2}$, O. O. Shendrikova ${ }^{3}$ \\ ${ }^{1}$ Voronezh State University, 1, University Sq., Voronezh, Russia, 394018 \\ ${ }^{2,3}$ Voronezh State Technical University, Voronezh, Russia, 394026
}

Cite as: Golovin, S.V., Lutsenko, M. S., Shendrikova, O. O. (2020) On the issue of control over the procurement of goods, works and services of organizations of the commercial and public sector of the economy. Proceedings of Voronezh State University. Series: Economics and Management. 4, 15-29. (In Russ., abstract in Eng.). DOI: 10.17308/econ.2020.4/3189

\begin{abstract}
Purpose. For a long time, there has been a tendency to increase the number of violations in the implementation of procurement procedures. Violations of the procurement procedure at enterprises of the public and private sectors of the economy occur at any stage of the process, starting with the tender procedures and ending with the execution of the contract. In this regard, it becomes relevant to exercise internal control over the procurement process in the public and private sectors of the economy.

Objectives. In the article, the authors identify the features of the organization of internal control, comparison of the procurement process in the field of goods, works and services in Russian commercial organizations, state corporations and state institutions. Comparative characteristics of procurement procedures in the public and private sectors of the economy.

Methodology. In the process of achieving these goals, the methods of scientific knowledge were used: dialectical; analysis and synthesis, comparison. The study is based on the study of current scientific and periodical economic literature.

Results. The results of comparing the procurement control procedures in the public and private sectors of the economy allow us to identify important distinctive features of control in the public sector of the economy. Also, based on the practice of procurement activities of state corporations, the main reasons for violations of the legislation in the field of procurement of goods, works and services, as well as ways out of the current situation, are considered. The authors propose measures to monitor the implementation of procurement, which can be carried out in practice by employees of both public and private structures.

Key words: procurement of goods, works and services, control in the field of procurement, internal control, state Corporation, commercial enterprise, customer control, public sector of the economy, private sector of the economy.
\end{abstract}

\section{Conflict of Interest}

The authors declare the absence of obvious and potential conflicts of interest related to the publication of this article.

\section{References}

1. Antonopoulos, A. M. (2014) Mastering Bitcoin. CA: Sebastopol, O’Reilly Media, Inc.

2. Peemöller, V. \& Kregel, J. (2010) Grundlagen der Internen Revision: Standards, Aufbau und Führung. Berlin, Schmidt. (In German)

3. Schneider, D. (2005) Controlling als postmodernes Potpourri. Controlling, 17, 65-69. (In German).

4. Astapovich, O. G. (2020) [Contemporary international competitive tenders: concept, features, trends]. Pravo. Economika. Psihologia. 1 (17), 10-15. (In Russ.).
5. Bakhvalov, V. L. (2019) [Questions of effective control in the sphere of public procurement]. Zhurnal Byudzhet. 3 (195), 45-47. (In Russ.).

6. Bogomazova, E. K. (2018) [Main goals and objectives of procurement audit]. Innovatsii $i$ investitsii. 5, 155-156. (In Russ.).

7. Vaypan, V. A. (2017) [Condition, problems and perspectives of contract system development]. Zhurnal predprinimatelskogo i korporativnogo prava.4, 9-12. (In Russ.).

8. Golovin, S. V. (2020) [Features of the modern stage of control in the sphere of procurement of state institutions]. Audit. 10, 30-34. (In Russ.). 
9. Golovin, S. V. \& Kapranchikov, I. S. (2019) [Features of procurement activities in public health service]. Modern economics: problems and solutions. 4 (112), 16-23. (In Russ.).

10. Gorlova, I. R., Musina, D. R. \& Boldyrev, E. S. (2018) [Improving the procurement process at an oil-producing enterprise]. Evraziiskii yuridicheskii zhurnal. 1, 383-385. (In Russ.).

11. Goryunova, V. V. (2016) [Audit in the sphere of procurement of goods, works and services for state needs]. Ekonomika I predprinimatelstvo. 12-1 77, 907-909. (In Russ.).

12. Zotkina, M. A. (2017) Conditions of participation of motor transport enterprises in tender procedures. Vestnik Sibirskogo gosudarstvennogo avtomobilno-dorozhnogo universiteta. 4-5 (56-57), 159-165. (In Russ.).

13. Leibert, T. B., Khalikova, E. A. \& Tretyakov, T. A. (2019) [Compliance control of purchases related to investment activities of companies]. Ekonomika i upravlenie. 6 (150), 119-122. (In Russ.).

14. Makarova, V. V. (2020) [Evaluation of the effectiveness of the contract system: Russian and foreign experience]. Aktualnye problemy i perspektivy razvitiya ekonomiki: rossiiskii i zarubezhnyi opyt. 1 (26), 21-25. (In Russ.).
15. Osodoeva, O. A., Sanzhin, B. B. \& Tsyrempilov, D. A. (2018) Development of public procurement in the republic of Buryatia. Ekonomicheskii vestnik Vostochno-Sibirskogo gosudarstvennogo universiteta tekhnologii i upravleniya. 6, 21-30. (In Russ.).

16. Paulov, P. A. \& Silantieva, K. V. (2018) [State regulation of procurement activities]. Bulletin of science and practice. 4 (12), 442-446. (In Russ.).

17. Sayfullova, G. G. \& Khaytabaev, V. A. (2018) [Procedures of internal control in the preparation and conduct of tenders]. Nauka i obrazovanie transportu. 1, 160-161. (In Russ.).

18. Solostina, T. A. (2019) Audit in the field of procurement in the development of a new system of state procurement. Vestnik Rossiiskogo novogo universiteta. Seriya: Chelovek i obshchestvo. 3, 73-79. (In Russ.).

19. Ustinova, O. E. (2019) Foreign experience of public procurement management and features of Russian practice in the conditions of contract system reformation. Innovatsionnoe razvitie ekonomiki. 2 50, 183-187. (In Russ.).

20. Khalikova, E. A. \& Safiullin, I. I. (2017) [Improvement of the corporate procurement management system]. Evraziiskii yuridicheskii zhurnal. 9, 384-385. (In Russ.).
Sergey V. Golovin, Cand. Sc. (Eng.), Associate Professor of the Economic Analysis and Audit Department, Voronezh State University, Voronezh, Russian Federation

E-mail: golovin@econ.vsu.ru

ORCID ID: 0000-0002-9722-4523

Marina S. Lutsenko, Cand. Sc. (Econ.), Associate Professor of the Department of Economic Security, Voronezh State Technical University, Voronezh, Russian Federation

$$
\begin{aligned}
& \text { E-mail: luchiksan@rambler.ru } \\
& \text { ORCID ID: 0000-0002-2137-164X }
\end{aligned}
$$

Olesya O. Shendrikova, Cand. Sc. (Econ.), Associate Professor of the Department of Economic Security, Voronezh State Technical University, Voronezh, Russian Federation

E-mail: oli-shendro@yandex.ru

ORCID ID: 0000-0001-8975-2660

Received 30.10.2020

Accepted 15.12.2020 